\title{
HPLC Analysis of Manno-Oligosaccharides Derived from Saccharomyces cerevisiae Mannan Using an Amino Column or a Graphitized Carbon Column
}

\author{
Toshiko Tanimoto, ${ }^{*}$ Akiko Ikuta, Mayumi SugrYama, and Kyoko Koizumi ${ }^{1)}$ \\ School of Pharmaceutical Sciences, Mukogawa Women's University, 11-68 Koshien, Kyuban-cho, Nishinomiya 663-8179, \\ Japan. Received August 28, 2001; accepted November 8, 2001
}

\begin{abstract}
The chromatographic behavior of manno-oligosaccharides derived from Saccharomyces cerevisiae mannan on two kinds of HPLC columns, an aminopropyl-silica column or a graphitized carbon column (GCC), was investigated. The order of elution of manno-oligosaccharides on both columns with acetonitrile-water was almost the same, that is, the retention increased with increasing molecular size. However, the GCC made it possible to isolate completely two isomers of mannotrioses $\left(M_{3}-1\right.$ and $\left.M_{3}-2\right)$ with different linkage positions. We reinvestigated the structures of mannobiose $\left(M_{2}\right), M_{3} s$, and mannotetraose $\left(M_{4}\right)$ that were completely isolated by matrixassisted laser desorption ionization time-of-flight mass spectrometry (MALDI-TOF-MS) and NMR spectroscopy.
\end{abstract}

Key words HPLC; graphitized carbon column; manno-oligosaccharide; Saccharomyces cerevisiae mannan; NMR

The structure of Saccharomyces cerevisiae (commercial baker's yeast) mannan has been reported by many investigators. $^{2-8)}$ It is highly branched and contains $1 \rightarrow 2,1 \rightarrow 3$, and $1 \rightarrow 6$ linkages. Mannan has been proposed to have a "backbone" of $1 \rightarrow 6$-linked mannose units with $1 \rightarrow 2$ - and $1 \rightarrow 3$ linked side chains that average about two sugar units in length. $^{6-8)}$ Stewart and Ballou, ${ }^{8)}$ while not offering any particular ratio or order of units in the chain, have suggested that the mannan from $S$. cerevisiae has a structure like that depicted in Fig. 1. NMR spectra of mannans have been analyzed, ${ }^{9-12)}$ and recently Vinogradov et al. ${ }^{13)}$ have deduced the complete structure of mannan and assessed the ratio of different side chains on the basis of high-field NMR spectroscopy data.

Thus far, the deacetylated products of an acetolysate of yeast mannan have been separated by gel filtration, and the structures of each, along with the branch point of linkage, have been mainly established by methylation analysis. Although structural analyses of oligosaccharides of the polysaccharide mannan and mannoprotein using NMR spectroscopy have been performed, ${ }^{9-13)}$ pure oligosaccharides could rarely be obtained.

We have chemically synthesized the branched cyclodextrins glucosyl-cyclodextrins ${ }^{14,15)}$ and galactosyl-cyclodextrins ${ }^{16)}$ and are now trying to synthesize branched cyclodextrins with mannose on the nonreducing ends in their side chains, because such compounds are expected to be useful as drug carriers in targeted drug delivery systems. To obtain the pure manno-oligosaccharides as side chains, we tried to isolate them from $S$. cerevisiae by isolating acetolysis fragments. Using an aminopropyl-silica column, the products were completely isolated as mannobiose $\left(\mathrm{M}_{2}\right)$, mannotrioses $\left(\mathrm{M}_{3} \mathrm{~s}\right)$, and mannotetraose $\left(\mathrm{M}_{4}\right)$. Also, using a graphitized carbon column (GCC), two isomers of $M_{3} s, M_{3}-1$ and $M_{3}-2$, were obtained. Their structures were elucidated by matrix-assisted laser desorption ionization time-of-flight mass spectrometry (MALDI-TOF-MS) and NMR spectroscopy.

\section{Experimental}

HPLC Conditions HPLC analyses were performed with a Jasco 980PU pump and a Shodex RI-71 monitor. The columns used were a Hibar LiChroCART $\mathrm{NH}_{2}(250 \times 4.0 \mathrm{~mm}$ i.d., Kanto Chemical $)$ and a Hypercarb
( $5 \mu \mathrm{m}, 100 \times 4.6 \mathrm{~mm}$ i.d., Thermo Hypersil). For preparative HPLC, a TSKgel Amide- 80 column $(300 \times 21.5 \mathrm{~mm}$ i.d., Tosoh) and a Hypercarb ( $5 \mu \mathrm{m}, 100 \times 10 \mathrm{~mm}$ i.d., Thermo Hypersil) were used. HPLC analyses at constant temperature were conducted using a column oven CA-202 (Flom).

MS MALDI-TOF-MS was performed in the positive-ion mode on a Vision 2000 reflector-type TOF instrument (Thermo Bioanalysis). The other conditions for measurements were as reported in a previous paper. ${ }^{17)}$

NMR ${ }^{1} \mathrm{H}$ - and ${ }^{13} \mathrm{C}-\mathrm{NMR}$ spectra data were recorded for $6-10 \%$ solutions in $\mathrm{D}_{2} \mathrm{O}$ at $50{ }^{\circ} \mathrm{C}$ with a Jeol GSX-500 spectrometer. Chemical shifts were expressed in ppm downfield from the signal of $\mathrm{Me}_{4} \mathrm{Si}$ referenced to external 1,4-dioxane $(67.40 \mathrm{ppm})$. The other conditions for ${ }^{1} \mathrm{H}-{ }^{1} \mathrm{H}$ correlation spectroscopy (COSY) and ${ }^{1} \mathrm{H}-{ }^{13} \mathrm{C}$ COSY measurements were as reported in a previous paper. ${ }^{18)}$

Isolation of Mannan Pressed baker's yeast $(2.0 \mathrm{~kg})$ was crumbled into $900 \mathrm{ml}$ of water and $90 \mathrm{ml}$ of $0.2 \mathrm{M}$ citrate buffer solution ( $\mathrm{pH} 7.0$ ), and the mixture was autoclaved at $125^{\circ} \mathrm{C}$ for $2 \mathrm{~h}$. Crude mannan $(30.0 \mathrm{~g})$ was obtained and purified according to the method described by Peat et al., ${ }^{5)}$ with a yield of $18.8 \mathrm{~g}$.

Acetolysis of Mannan and Isolation of Mannose Oligosaccharides Mannan $10.1 \mathrm{~g}$ was dissolved in a mixture of $52.5 \mathrm{ml}$ of acetic acid-acetic anhydride-sulfuric acid $(10: 10: 1 \mathrm{v} / \mathrm{v})$, and the mixture was stirred at $38^{\circ} \mathrm{C}$ for $23 \mathrm{~h}$, then at room temperature for $40 \mathrm{~h}$ according to the method described by Peat et al. ${ }^{5}$ and Lee and Ballou. $\left.{ }^{6}\right)$ The progress of the reaction was monitored by TLC on Silica Gel 60 (Merck) (benzene-acetone 2:1). After neutralization with sodium hydrogen carbonate, the reaction products were extracted with chloroform. The chloroform layer was evaporated to dryness to yield $7.0 \mathrm{~g}$ of a mixture of sugar acetates. Most of the acetolysate was fractionated by centrifugal chromatography (Harrison Centrifugal ThinLayer Chromatotron, Model 7924) with hexane-acetone, and then each fraction was deacetylated. $\mathrm{M}_{2}, \mathrm{M}_{3} \mathrm{~s}$, and $\mathrm{M}_{4}$ were purified by HPLC on a TSKgel Amide- 80 column $(300 \times 21.5 \mathrm{~mm}$ i.d. $)(60: 40$ acetonitrile-water; flow rate, $4.0 \mathrm{ml} / \mathrm{min}$; detector, Shodex RI-71) and two mannotrioses were isolated on a Hypercarb $(100 \times 10 \mathrm{~mm}$ i.d.) $(0.5: 99.5$ acetonitrile-water; flow rate, $0.5 \mathrm{ml} / \mathrm{min}$; detector, Shodex RI-71; temperature, $50^{\circ} \mathrm{C}$ ).

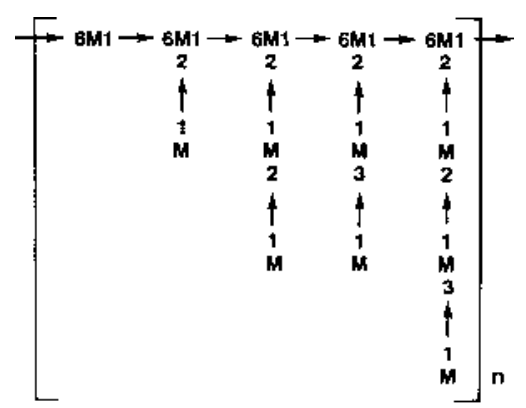

Fig. 1. Structure of Mannan from S. cerevisiae as Proposed by Stewart and Ballou ${ }^{8)}$ 


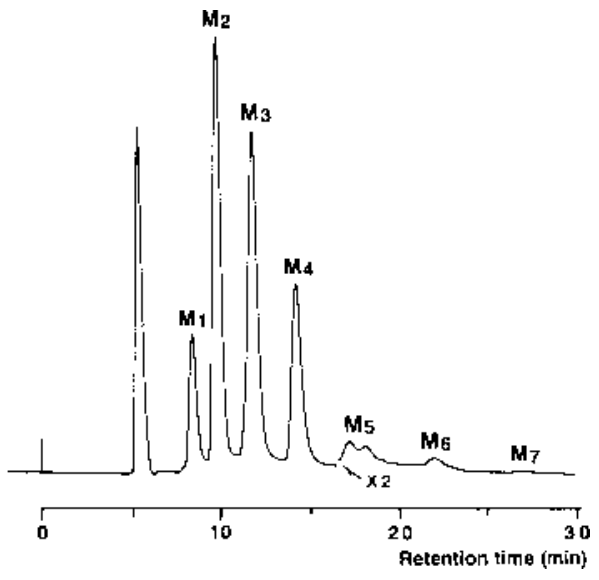

Fig. 2. Elution Profile of Mannose Oligosaccharides from S. cerevisiae

Chromatographic conditions: column, Hibar LiChroCART $\mathrm{NH}_{2}(250 \times 4.0 \mathrm{~mm}$ i.d.); eluent, $65: 35$ acetonitrile-water; flow rate, $0.5 \mathrm{ml} / \mathrm{min}$; detector, Shodex RI-71.

\section{Results and Discussion}

A portion of the acetolysate obtained (100 mg) was deacetylated in the usual way, and then HPLC analyses of manno-oligosaccharides were performed with an aminopropyl-silica column and a GCC. The elution profiles are shown in Figs. 2 and 3, respectively. Figure 2 shows the elu-

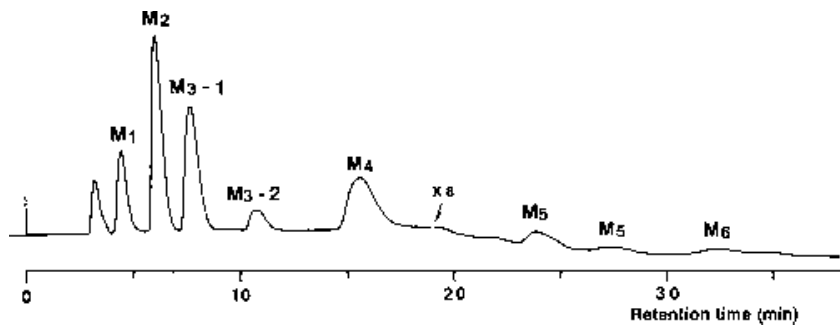

Fig. 3. Elution Profile of Mannose Oligosaccharides from S. cerevisiae

Chromatographic conditions: column, Hypercarb $(100 \times 4.6 \mathrm{~mm}$ i.d.); eluent, $1.0 \%$ acetonitrile aqueous solution containing $1.0 \mathrm{~mm}$ sodium hydroxide; flow rate, $0.5 \mathrm{ml} / \mathrm{min}$; detector, Shodex RI-71; temperature, $20^{\circ} \mathrm{C}$.
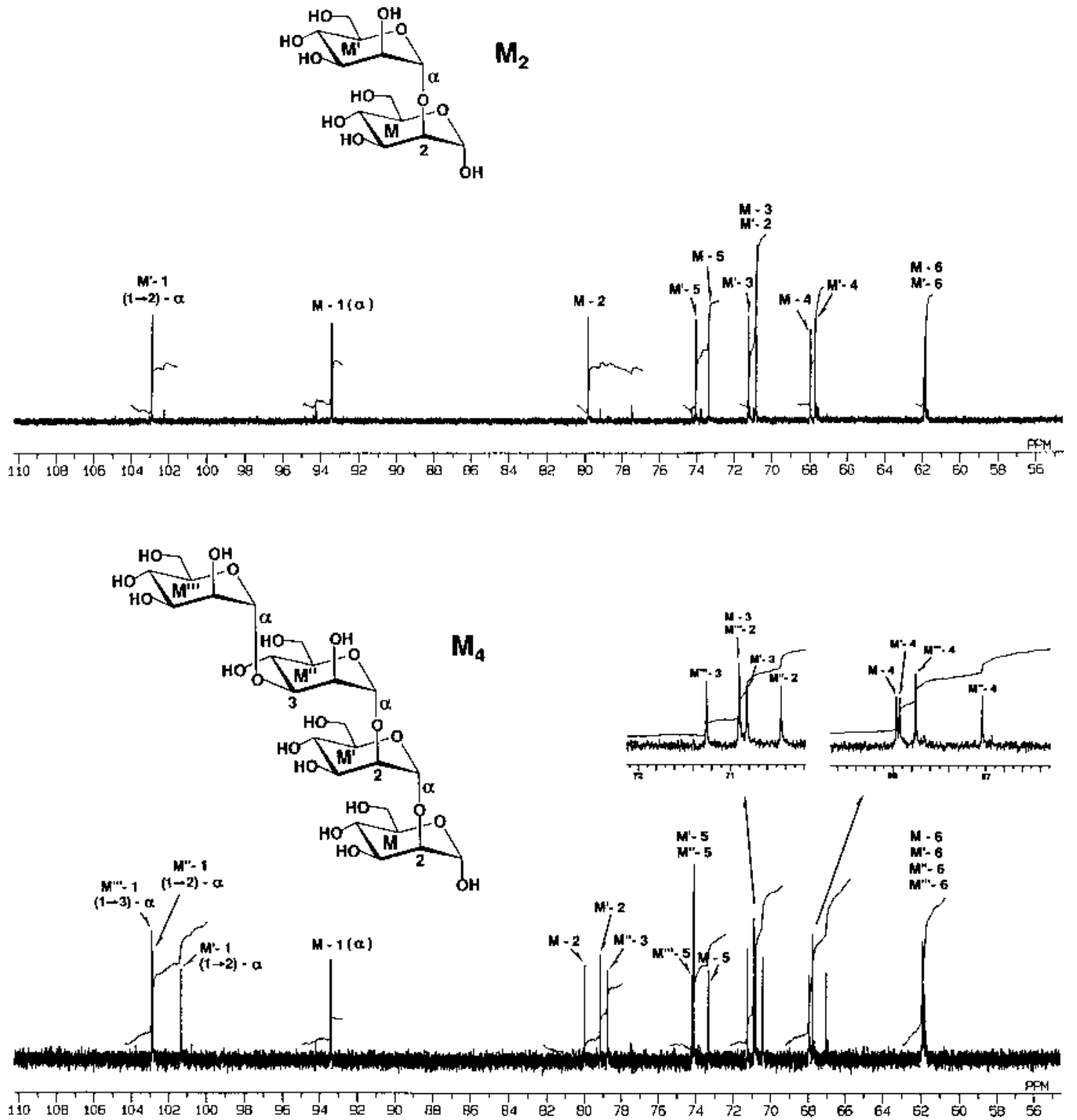

Fig. 4. ${ }^{13} \mathrm{C}$-NMR Spectra of $\mathrm{M}_{2}$ and $\mathrm{M}_{4}$ Measured in $\mathrm{D}_{2} \mathrm{O}$ at $125.65 \mathrm{MHz}$ 
tion profile of the product of acetolysis; the ratio of mannose $\left(M_{1}\right): M_{2}: M_{3} s: M_{4}:$ mannopentaose $\left(M_{5}\right)$ : mannohexaose $\left(M_{6}\right)$ was $14: 44: 44: 38: 2: 1$. In the analysis using this aminopropyl-silica column, the two $\mathrm{M}_{3} \mathrm{~s}\left(\mathrm{M}_{3}-1\right.$ and $\left.\mathrm{M}_{3}-2\right)$ were not separated. Retention on an amino column is similar to that on an anion-exchange resin, and the retention rate increases with increasing molecular size. ${ }^{19)}$

Figure 3 shows the elution profile of the same acetolysate on a GCC with $1 \mathrm{~mm}$ sodium hydroxide solution containing $1.0 \%$ acetonitrile. The ratio of $\mathrm{M}_{1}: \mathrm{M}_{2}: \mathrm{M}_{3}-1: \mathrm{M}_{3}-2: \mathrm{M}_{4}$ : $\mathrm{M}_{5}: \mathrm{M}_{6}$ was $36: 92: 79: 21: 83: 2: 1$. Two $\mathrm{M}_{3} \mathrm{~s}\left(\mathrm{M}_{3}-1\right.$ and $M_{3}-2$ ) were clearly separated, and the ratio of $M_{3}-1$ and $M_{3}-2$ was $3.7: 1$. Koizumi et $a .^{20)}$ reported the first use of this
GCC for the separation of carbohydrate compounds. According to the manufacturer's description, the surface of the GCC packing is flat, which enables unique selectivity and the ability to resolve isomeric and closely related compounds. Retention on a GCC occurs mainly by an adsorption mechanism. In general, there is more retention of planar than nonplanar molecules. For a series of saccharides with the same molecular configuration, the retention rate increases with increasing molecular size. The hydrophobicity of the GCC is greater than those of other reverse-phase materials. A column with a highly structured graphite surface offers chemical and physical stability to enable repeated use without loss of performance or reproducibility. The conditions
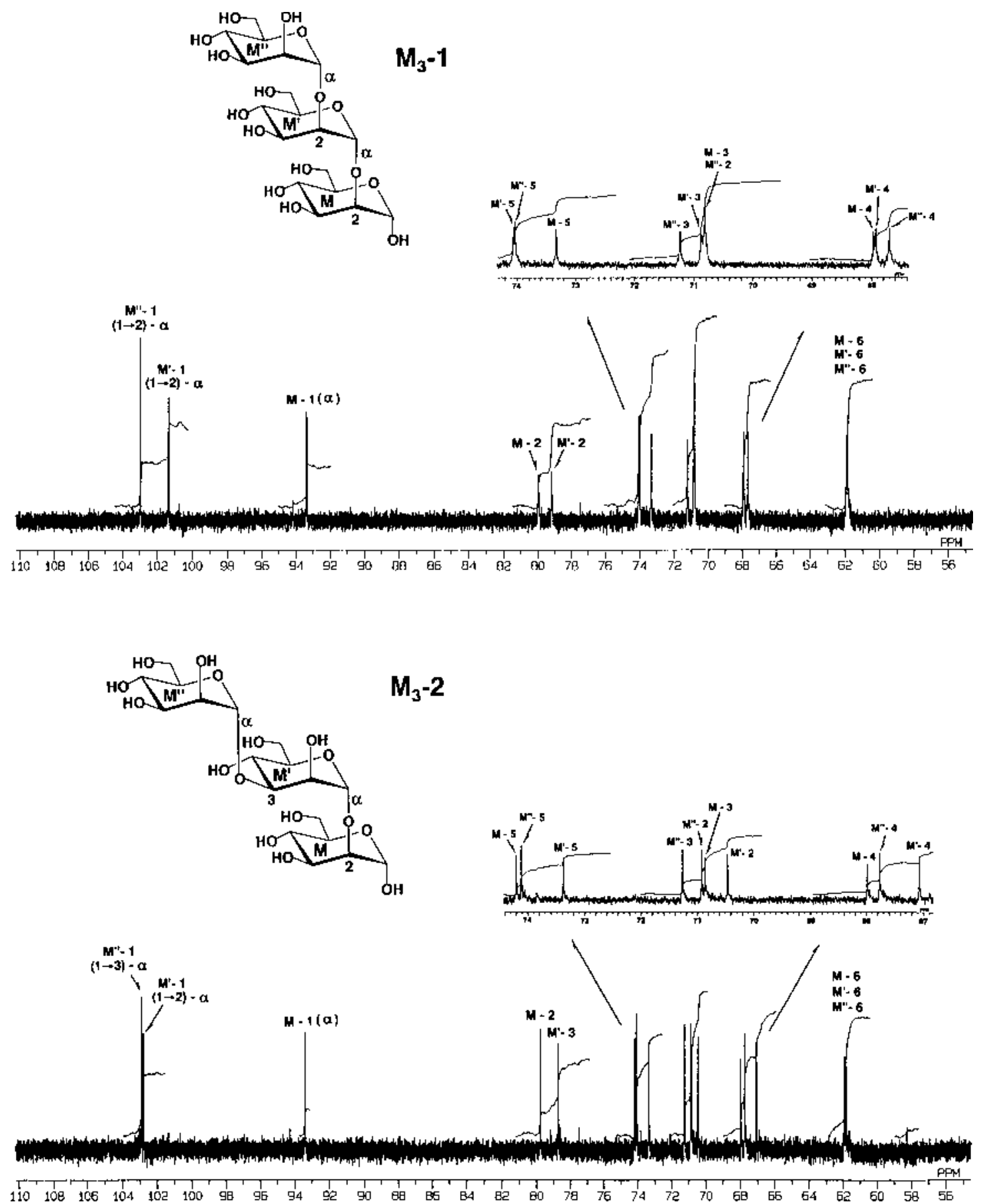

Fig. 5. ${ }^{13} \mathrm{C}-\mathrm{NMR}$ Spectra of $\mathrm{M}_{3}-1$ and $\mathrm{M}_{3}-2$ Measured in $\mathrm{D}_{2} \mathrm{O}$ at $125.65 \mathrm{MHz}$ 
used should be applicable to the analyses of high-mannose oligosaccharides in glycoproteins.

Most of the acetolysate was fractionated by centrifugal chromatography with hexane-acetone, and then each fraction was deacetylated. The main products, $\mathrm{M}_{2}, \mathrm{M}_{3} \mathrm{~s}$, and $\mathrm{M}_{4}$, were isolated and purified by HPLC on a TSKgel Amide- 80 column $(300 \times 21.5 \mathrm{~mm}$ i.d.) with $60: 40$ acetonitrile-water, and two $\mathrm{M}_{3} \mathrm{~s}$ were isolated on a Hypercarb $(100 \times 10 \mathrm{~mm}$ i.d.) with $0.5: 99.5$ acetonitrile-water. The molecular weights of $\mathrm{M}_{2}, \mathrm{M}_{3} \mathrm{~s}$, and $\mathrm{M}_{4}$ were confirmed to be $365.4,527.6$, and 689.6 , respectively, based on each molecular ion peak in the positive-ion mode $[\mathrm{M}+\mathrm{Na}]^{+}$by TOF-MS. To analyze their structures in detail, the NMR analysis was performed using ${ }^{1} \mathrm{H}-{ }^{1} \mathrm{H}$ COSY and ${ }^{1} \mathrm{H}-{ }^{13} \mathrm{C}$ COSY measurements, and all carbons in the spectra of $\mathrm{M}_{2}, \mathrm{M}_{3}-1, \mathrm{M}_{3}-2$, and $\mathrm{M}_{4}$ were completely assigned. The assignments of C-6 signals were confirmed by distortionless enhancement by the polarization transfer (DEPT) method. Figures 4 and 5 show ${ }^{13} \mathrm{C}-\mathrm{NMR}$ spectra of $M_{2}$ and $M_{4}$, and $M_{3}-1$ and $M_{3}-2$, respectively. The structures of $\mathrm{M}_{2}, \mathrm{M}_{3}-1, \mathrm{M}_{3}-2$, and $\mathrm{M}_{4}$ were identified as $\mathrm{M}$ $(1 \alpha) \rightarrow 2 \mathrm{M}, \mathrm{M}(1 \alpha) \rightarrow 2 \mathrm{M}(1 \alpha) \rightarrow 2 \mathrm{M}, \mathrm{M}(1 \alpha) \rightarrow 3 \mathrm{M}(1 \alpha) \rightarrow$ $2 \mathrm{M}$, and $\mathrm{M}(1 \alpha) \rightarrow 3 \mathrm{M}(1 \alpha) \rightarrow 2 \mathrm{M}(1 \alpha) \rightarrow 2 \mathrm{M}$, respectively. These findings match the structure presented in Fig. 1.

Acknowledgment The authors thank Dr. A. Misaki (professor emeritus of Osaka City University) for helpful discussions on how to obtain mannooligosaccharides. We also thank Professor M. Yamaki and her staff (Mukogawa Women's University) for recording and measuring the NMR spectra.

\section{References and Notes}

1) Deceased August 16, 2000.
2) Haworth W. N., Hirst E. L., Isherwood F. A., J. Chem. Soc., 1937, 784-791.

3) Peat S., Whelan W. J., Edwards T. E., J. Chem. Soc., 1958, 38623868.

4) Peat S., Turvey J. R., Evans J. M., J. Chem. Soc., 1958, 3868 - 3870.

5) Peat S., Whelan W. J., Edwards T. E., J. Chem. Soc., 1961, 29-34.

6) Lee Y. C., Ballou C. E., Biochemistry, 4, 257-264 (1965).

7) Stewart T. S., Mendershausen P. B., Ballou C. E., Biochemistry, 7, 1843-1854 (1968).

8) Stewart T. S., Ballou C. E., Biochemistry, 7, 1855-1863 (1968).

9) Tsai P. K., Frevert J., Ballou C. E., J. Biol. Chem., 259, 3805-3811 (1984).

10) Hernandez L. M., Ballou L., Alvarado E., Tsai P. K., Ballou C. E., J. Biol. Chem., 264, 13648-13659 (1989).

11) Hernandez L. M., Ballou L., Alvarado E., Gillece-Castro B. L., Burlingame A. L., Ballou C. E., J. Biol. Chem., 264, 11849-11856 (1989).

12) Alvarado E., Ballou L., Hernandez L. M., Ballou C. E., Biochemistry, 29, 2471-2482 (1990).

13) Vinogradov E., Petersen B., Bock K., Carbohydr. Res., 307, 177-183 (1998).

14) Tanimoto T., Tsujikawa J., Koizumi K., Chem. Pharm. Bull., 40, 1125-1129 (1992)

15) Tanimoto T., Sakaki T., Koizumi K., Carbohydr. Res., 267, 27-37 (1995).

16) Ikuta A., Koizumi K., Tanimoto T., J. Carbohydr. Chem., 19, 13-23 (2000).

17) Koizumi K., Tanimoto T., Kubota Y., Kitahata S., Carbohydr. Res., 305, 393-400 (1998).

18) Koizumi K., Tanimoto T., Okada Y., Takeyama S., Hamayasu K., Hashimoto H., Kitahata S., Carbohydr. Res., 314, 115-125 (1998).

19) Koizumi K., Utamura T., Okada Y., J. Chromatogr., 321, 145-157 (1985).

20) Koizumi K., Okada Y., Fukuda M., Carbohydr. Res., 215, 67-80 (1991). 